\title{
Coping with the COVID-19 Pandemic: Efficiency and Prospects in Plasma Donors' Perceptions
}

\author{
Artem Lytovchenko [0000-0002-1439-5213], Olena Muradyan * [0000-0003-0990-9635], \\ Dmytro Chumachenko ${ }^{\text {[0000- 0003-2623-3294] }}$ \\ V.N. Karazin Kharkiv National University, Ukraine \\ *o.s.muradyan@karazin.ua
}

\begin{abstract}
In connection with the continuation of the Covid-19 pandemic, the relevance of information promotion of anti-pandemic measures is becoming more urgent. Public opinion on these measures is mixed; there is an active movement of the socalled anti-vaxers. The article explores the possibility of involving a group of plasma donors as potential opinion leaders in the informational promotion of measures to combat the pandemic. To determine the potential of this group in promoting measures to combat the pandemic, it is necessary to find out their attitude to these measures and assess the prospects for promoting these measures. The article presents an analysis of the results of a sociological survey of plasma donors $(\mathrm{n}=542) .25 \%$ of respondents consider mass vaccination the most effective anti-pandemic agent, $21 \%$ - mask regime, 20\% - disinfection of transport and public places. Most of the respondents believe that information from scientific research can convince people to vaccinate, and $12 \%$ are counting on a wide information campaign. The results of the pairwise correlation and the constructed classification tree show that slightly more than a third of the respondents can act as the core of the information promotion of mass vaccination and other measures to combat the pandemic: these are plasma donors with completed secondary or higher education, who are 1) guided by the opinion of medical professionals and WHO representatives and are 2) optimistic assess the readiness of their environment for vaccination.
\end{abstract}

Keywords: COVID-19, mass vaccination, plasma donors, opinion leaders, classification tree analysis.

\section{INTRODUCTION}

The Covid-19 pandemic continues to be a significant factor in global social processes. The fight against the pandemic and its consequences remains urgent. The solution of this problem requires not only a sanitaryepidemiological and pharmacological, but also a sociological approach. There is a clear need to understand the social factors of the spread of diseases and also the social barriers and obstacles that pass in the systemic fight against the pandemic [1-5].

One of the most difficult barriers is social rejection of anti-pandemic measures. The basis of this rejection is diverse: tiredness from quarantine restrictions, fear of economic losses due to lockdowns, and the activity of anti-vaccination propaganda. In such conditions, work with mass forms of social consciousness, such as public opinion and public mood, acquires special importance; the importance of information policy during a pandemic is emphasized by scientists [6,7].

Today, in various countries of the world, one can observe how official - national, international - informing agents are not effective enough in promoting antipandemic measures. In many European, North American countries, massive protests against various anti-pandemic measures break out. At the same time, various opinion leaders, from video bloggers to archaically skeptical nursing staff, play a significant role in spreading mistrust in the measures to combat the pandemic [8] In the same time, this situation requires attention to the possibility of using opinions in overcoming barriers in the mass consciousness in relation to anti-pandemic measures [9]. Here we do not mean individual actors, social groups with special status characteristics, qualitative tools for using the information transmitted by such systems as factors to increase the confidence of the masses. Plasma donors can be one of these groups and will be discussed in more detail in our article [10]. In order to assess the potential of this group as an agent of anti-pandemic informing, it is necessary to understand what attitude towards pandemic measures prevails among the majority of representatives of this group and to what extent they are ready to be participants in anti-pandemic informing $[11,12]$. The extent to which the group itself is optimistic 
about the progress of pandemic measures can also be an important factor in the willingness of the group to take on the role of "locomotive" of such progress. So we are faced with a clear research question that determines the purpose of this publication - to characterize the perceptions of plasma donors about the effectiveness and prospects of anti-pandemic control.

\section{METHODOLOGY}

Within the framework of research theme No. 0121U109814 "Sociological and Mathematical Modeling of the Effectiveness of Managing Social and Epidemic Processes to Ensure the National Security of Ukraine", an online survey of plasma donors was carried out (it was targeted personal mailing of questionnaires by e-mail and we used the database of plasma donors). A preliminary analysis of the results of the study, the results of which are presented in our previous articles, was carried out on a total of 437 respondents. The total number of respondents in the end was 542 plasma donors; a special sample within plasma donors was not used, since the purpose of the study was consistent with a situation in which responses from the most active part of the group were collected. Those who voluntarily responded to the optional opportunity for them to fill out a sociological questionnaire are more likely to respond to the call to take part in informative support. And vice versa: if this active core demonstrates a pessimistic attitude towards the prospects of anti-pandemic fight, then this will be enough to consider the potential of the entire group as low. The responses were collected using a Google form; the resulting data array was exported in Excel format for further processing in the IBM SPSS Statistics 23 package.

The central indicators in the study for our tasks were the questions "What measure against the pandemic do you consider the most effective?" (nominal scale, the only choice), "Do you think your family and friends would agree to be vaccinated?", "Do you think your friends and acquaintances would agree to be vaccinated?" (both questions with the same ordinal scale of answers), as well as "What arguments and measures can, in your opinion, convince a person of the need to be vaccinated?" (nominal scale, only choice). The first indicator makes it possible to clarify the views of the respondents about anti-pandemic prevention in general, the remaining indicators are aimed at the most promising anti-pandemic agent according to today's views - vaccination.

\section{RESULTS}

Plasma donors consider mass vaccination to be the most effective means of combating the pandemic (24.5\%). There are slightly fewer supporters of the mask regime $(21,2 \%)$ and disinfection of transport and public places $(19.5 \%)$ as the leading agents in terms of effectiveness. Other suggested means lag behind noticeably. Of particular note is the relatively high percentage of plasma donors who believe that no measures to combat the pandemic are needed (Figure 1); considering that we are dealing with the most active part of the group, presumably more progressively disposed towards the anti-pandemic fight than the general population, this should be indicative of alarm.

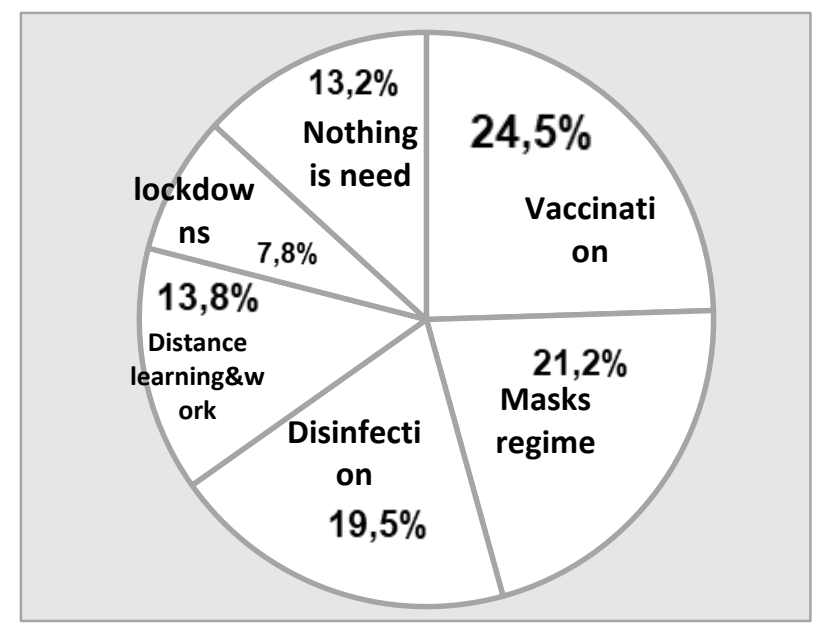

Figure 1 Opinion of plasma donors on the most effective measures to combat the COVID-19 pandemic (in\% of respondents, $n=538$ ). Source - author's research

We also note that in a similar question, but with multiple choices of answers, the most popular measure to combat the pandemic was mask regime $(54,2 \%)$, followed by disinfection of transport and public places $(50.4 \%)$, while mass vaccination was chosen by $31,2 \%$. The difference between the relative and absolute recognition of the effectiveness of vaccination is $6,7 \%$, while for the mask regime and disinfection, this figure is respectively $30 \%$ and $31.1 \%$; the greater this distance, the lower the "competitiveness" of a particular control measure from the point of view of plasma donors.

Readiness assessments to vaccinate relatives and families of the respondents, as well as friends and acquaintances, predictably demonstrate a slight decrease in respondents' confidence when they characterize the readiness of friends and acquaintances (see Figure 2). It is unlikely that this decrease deserves a separate interpretation - and not only because of its insignificance, but also because of the obviously lower awareness of the respondents about the views and intentions of friends and acquaintances in comparison with relatives and family. The part of those who found it difficult to answer is the same for both cases and amounts to $11 \%$ (not shown in the graphical display).

Overall, positive responses (uniting all the levels of readiness of the social environment) amount to $57-58 \%$, which can be considered as a very restrained optimism. Almost a third of plasma donors believe that the readiness of their environment to be vaccinated is equal or tends to zero. 


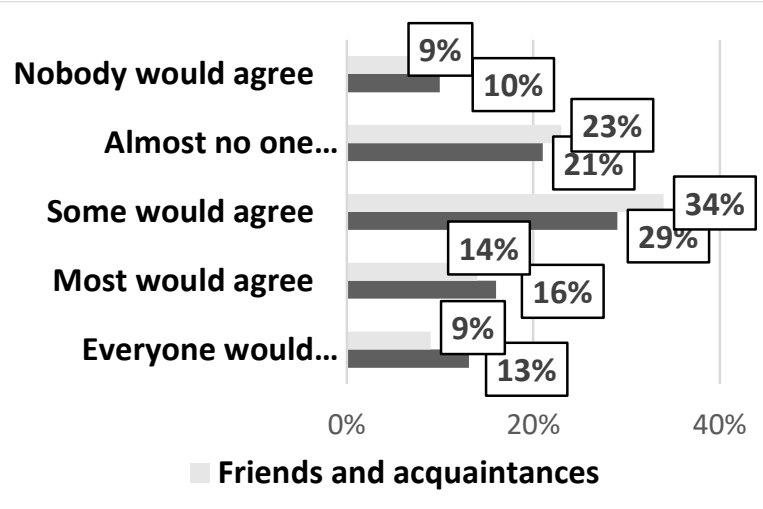

Figure 2 Readiness of the social environment for vaccination: plasma donors evaluation (in \% of respondents, $n=542$ ). Source - author's research

What is specific, this share is noticeably higher than the share of those respondents who believe that nothing can convince people to get vaccinated: among the respondents, there were $18 \%$ of them (see Figure 3). The distribution of the remaining answer options indirectly shows those fears about vaccination that the respondents either personally share or consider to be significant for the mass consciousness. First of all, these are doubts about the safety of vaccines and a lack of research data on their effectiveness. Accordingly, $60 \%$ of plasma donors consider the scientific evidence for the safety and efficacy of vaccines to be potentially compelling; at the same time, information activities, including the participation of opinion leaders, are considered effective in total by $22 \%$ of respondents.

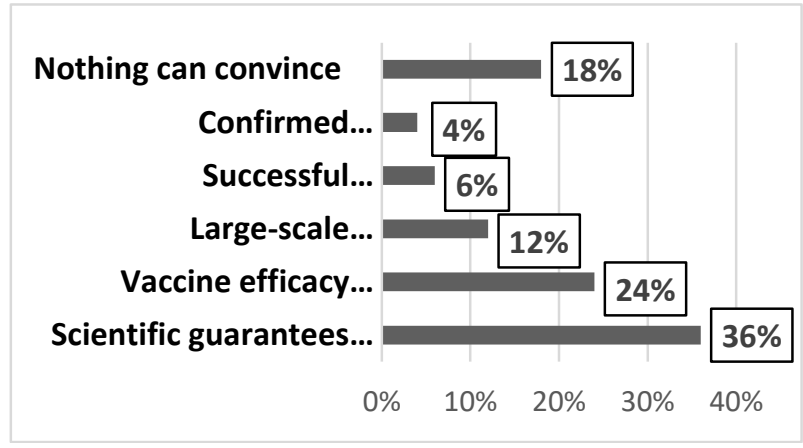

Figure 3 Effectiveness of arguments about the need for vaccination: plasma donors evaluation (in\% of respondents, $n=539)$. Source - author's research

\section{ANALYSIS OF RESULTS AND DISCUSSION}

Taking into account that the distribution of assessments of readiness for vaccination of relatives and family, on the one hand, and friends and acquaintances, on the other, does not show any fundamental differences, we calculated an additional variable "Readiness for vaccination", combining the answers to both questions. For this variable, the array $(n=502$, excluding 40 people who found it difficult to answer both questions) was divided into the following three groups: pessimists those who assess their environment as unprepared to be vaccinated to varying degrees $(40,4 \%)$, neutrals - those who believe that the moderate part of the environment will agree to be vaccinated $(25,2 \%)$, and optimists, who consider their environment to be largely ready for vaccination $(34,4 \%)$. It can be assumed that this generalized assessment of the readiness of the environment for vaccination, if not reflects, then gives reason to make assumptions about the own attitude of plasma donors to vaccination, and about the level of their possible enthusiasm for the informational promotion of mass vaccination.

However, a separate study is required to test these assumptions. On the basis of the available array, we can only check what signs and conditions are associated with the assessment of plasma donors of the readiness of their environment for vaccination. Attempts to apply logistic regression analysis and cluster analysis have yielded no meaningful information. Therefore, using the calculated variable as a dependent, we built a classification tree (CHAID method, the minimum number of observations in the parent node is 100 , in the child node - 50; three branching levels; estimate 0,425 , standard error 0,022). The independent variables were age, gender, education, frequency of contacts at work, preferences of the main source of information about the COVID-19 pandemic, opinion about the most effective anti-pandemic agent, and ideas about the credibility of possible arguments for the need for vaccination. Figure 4 shows a diagram of the constructed classification tree (the decoding of the nodes is given in Table 1).

The first node, the largest one, reproduces the distribution according to the readiness of the environment for vaccination with minimal deviations from the initial one: the proportion of neutrals actually remains unchanged. This site brings together those who believe that all possible measures to combat a pandemic, except for vaccination, are most effective. Those who believe all the measures applied are unnecessary are represented in node number three: it is not surprising that the majority of them are those who consider their environment unprepared for vaccination. Taking into account our goal, the second node seems to be the most interesting: it represents a quarter of the entire array, these are respondents who consider vaccination to be the most effective means of combating a pandemic, and more than half of them $(56,7 \%)$ believe their environment is ready for vaccination. Further branching of this node was carried out on the basis of education, and in terminal node number 7, respondents with complete secondary and higher education, as well as with an academic degree, are represented. More than two-thirds of this subgroup is optimistic about the readiness of their environment to be 
vaccinated. This allows us to talk about the importance of the level of education, and the main characteristic is its completeness. Node 8 presents respondents with different versions of incomplete education - incomplete higher, secondary vocational and special. It can be assumed that this subgroup unites young people who are in the process of training or have recently completed it. Branching the first node to measure the effectiveness of the vaccine argument gives us three nodes. Node 4 brings together rational skeptics who lack scientific evidence for the effectiveness and safety of vaccines; the share of those who consider their environment not ready for vaccination is close to half here. Node 5 - these are those who consider the arguments of a public nature to be convincing: an information campaign, demonstrative vaccination. Almost two-thirds of this group believes their environment is ready to be vaccinated. Node 6 presents us with radical skeptics who do not believe in the credibility of any arguments in favor of vaccination; it is not surprising that almost three quarters of these people are convinced that those around them are not ready to get vaccinated. Thus, nodes No. 2, No. 5 and No. 7 show us that plasma donors with a completed and high level of education, who consider vaccination the most effective method of combating a pandemic, and a largescale information campaign, coupled with the successful vaccination of public figures, are able to convince people of the need for vaccination, as a rule, they believe their close social environment is ready to be vaccinated.

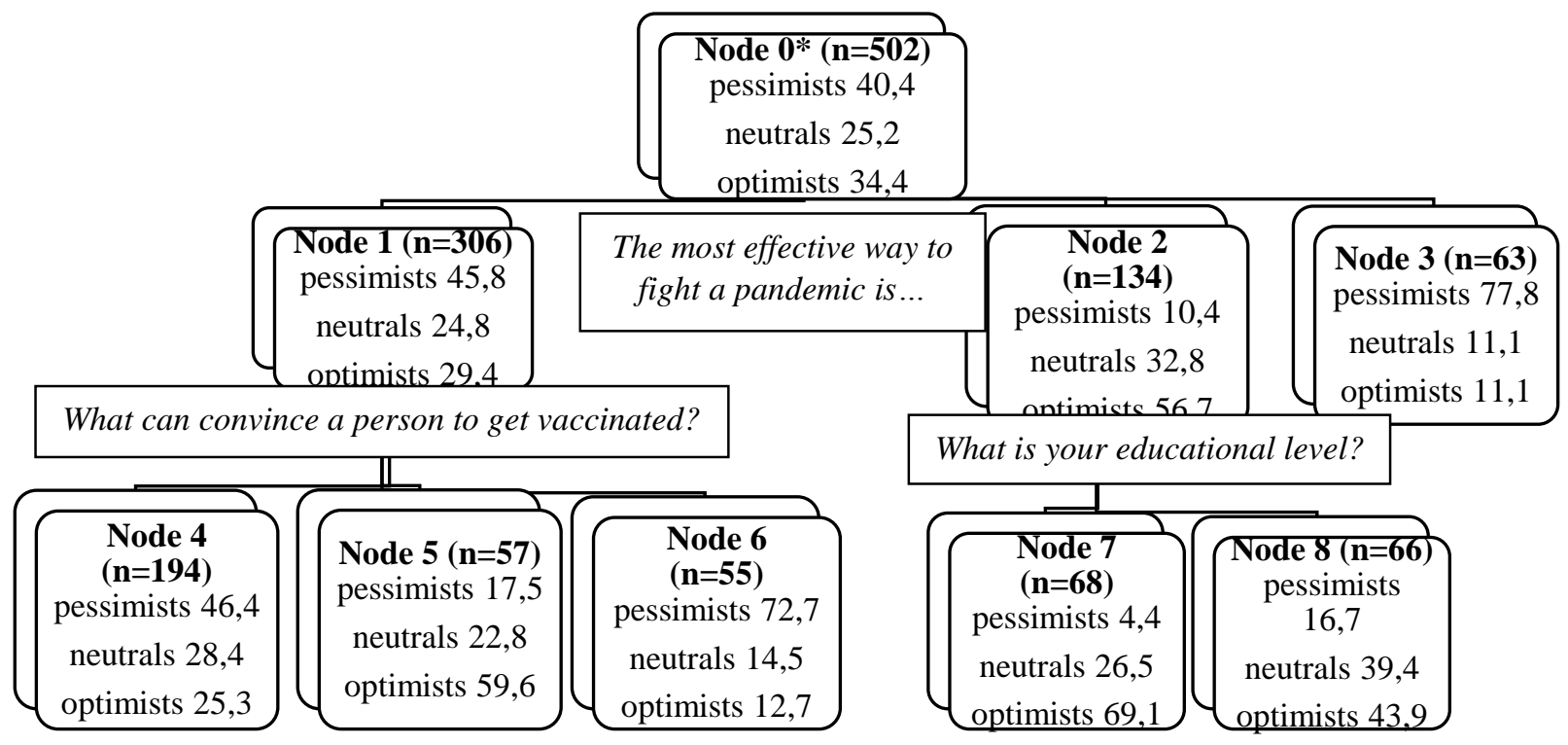

Figure 4 Classification of the dataset by assessing the readiness of their environment for vaccination (in $\%, \mathrm{n}$ is indicated for each node). Italics indicate the signs by which branching is carried out. The source is the author's data analysis.

Table 1. * Conditions for assigning respondents to a specific node of the classification tree

\begin{tabular}{|c|l|}
\hline Node, № & \multicolumn{1}{c|}{ Assignment condition (selected answer option) } \\
\hline Node $\mathbf{0}$ & Readiness of the environment for vaccination \\
\hline Node 1 & Mask regime, disinfection of transport and public places, distance, "lockdowns" \\
\hline Node 2 & Mass vaccination \\
\hline Node 3 & No action needed \\
\hline Node 4 & Vaccine efficacy research results, vaccine safety assurances, confirmed vaccination of politicians \\
\hline Node 5 & Large-scale information campaign; successful vaccination of public figures \\
\hline Node 6 & Nothing will convince \\
\hline Node 7 & Higher education or scientific degree, complete secondary education \\
\hline Node 8 & Secondary vocational, secondary specialized, incomplete higher education \\
\hline
\end{tabular}

The correlation between the willingness to vaccinate with age was significant (we assumed this even when working with the classification tree), with the opinion regarding the most convincing arguments in favor of the need for vaccination (which also manifested itself and was analyzed by us according to the results of the classification tree), and also with that Whose opinion do respondents listen to in Covid-19 issues.

We also carried out a pairwise correlation of the list of signs with the sign of the readiness of the environment for vaccination; the results are shown in Table 2. 
Table 2. Correlation of readiness to vaccinate with different features $* * *$.

\begin{tabular}{|c|c|c|c|c|c|c|c|c|}
\hline & 更 & Gender & $\begin{array}{l}\text { What is the } \\
\text { main source } \\
\text { of } \\
\text { information } \\
\text { about } \\
\text { Covid-19? }\end{array}$ & $\begin{array}{l}\text { Who do } \\
\text { you } \\
\text { listen to } \\
\text { about } \\
\text { Covid- } \\
19 \\
\text { mostly? }\end{array}$ & $\begin{array}{l}\text { What is the } \\
\text { most } \\
\text { effective } \\
\text { response to } \\
\text { the } \\
\text { pandemic? }\end{array}$ & $\begin{array}{l}\text { What can } \\
\text { convince a } \\
\text { person to the } \\
\text { need for } \\
\text { vaccination? }\end{array}$ & Education & $\begin{array}{l}\text { How } \\
\text { frequent } \\
\text { are } \\
\text { contacts } \\
\text { at work? }\end{array}$ \\
\hline $\begin{array}{l}\text { Pearson } \\
\text { correlation }\end{array}$ &,$- 137^{* * *}$ &,- 043 & ,021 &,$- 113^{*}$ &,- 052 &,$- 329^{* *}$ &,- 027 &,- 027 \\
\hline $\begin{array}{l}\text { Mean. } \\
\text { (double- } \\
\text { sided) }\end{array}$ & ,002 & ,334 & ,647 & ,012 & ,249 & ,000 &, 541 &, 549 \\
\hline $\mathrm{N}$ & 503 & 503 & 499 & 493 & 499 & 499 & 503 & 503 \\
\hline
\end{tabular}

The choice of a hypothetical authorities on Covid19 issues is associated with an assessment of the readiness of the social environment to be vaccinated in the following way. Those respondents who listen to the representatives of the Ministry of Health of Ukraine demonstrate the greatest bias in favor of the "optimists" (33\% of the "pessimists", $30 \%$ of the "neutrals" and $37 \%$ of the "optimists"); in the group of those who listen to medical professionals, this shift is already observed in the opposite direction $(39 \%, 27 \%$ and $34 \%$, accordingly). Surprisingly, however, there are noticeably more "pessimists" (47\%) among those who listen to the WHO representatives (or follow, for example [13-15]); according to this criterion, only those who prefer to listen to their friends and to the leaders of world powers ( $60 \%$ and $67 \%$ of "pessimists", respectively) are ahead of this group.

As for age, the group from 25 to 39 years old demonstrates a noticeable shift towards "pessimists" in comparison with other groups, and primarily due to the overflow of "neutrals" (Table 3). Otherwise, it can be argued that there is no fundamental influence of age on the assessment of the readiness of the environment for vaccination.

Table 3. The results of the conjugation of age and assessment of the readiness of the environment to be vaccinated (in \% for each age group) *

\begin{tabular}{|c|c|c|c|c|}
\hline Willingness & $18-20$ & $21-24$ & $25-39$ & $\begin{array}{c}40 \text { and } \\
\text { older }\end{array}$ \\
\hline Pessimists & $34 \%$ & $38,6 \%$ & $45,9 \%$ & $40,4 \%$ \\
\hline Neutrals & $26,6 \%$ & $27,1 \%$ & $22,0 \%$ & $25,2 \%$ \\
\hline Optimists & $39,4 \%$ & $34,3 \%$ & $32,1 \%$ & $34,4 \%$ \\
\hline
\end{tabular}

*- source: author's data analysis

\section{CONCLUSIONS}

Plasma donors in their assessments of antipandemic control measures take a position loyal to the existing medical consensus, calling mass vaccination, adherence to a mask regime, and disinfection of transport and public places the most effective means. However, more than $13 \%$, who believe that no control measures are needed, seem all the more significant if we consider that this answer was the only negative one of all those proposed. Therefore, these people are a convinced core of skeptics, who obviously believe, for one reason or another, that the pandemic is not worth attention, and the fight against it is an effort. The question of how you can convince people to vaccinate gives an even greater negative indicator: almost a fifth of the respondents are sure that nothing can convince people to get vaccinated. As a result, this also affects the assessment of the readiness for vaccination of the environment of plasma donors: more than $40 \%$ of the respondents consider this readiness to be low or zero. It is clear that their assessment can be distorted by various factors; however, firstly, we have no reason to believe the hypothetical distortion is significant, and secondly, for our general research question about the potential of a group of plasma donors as an agent of pandemic information, which determined the purpose of this article, the mentioned assessment is important in itself. It is unlikely that the part of plasma donors that adequately or not, but pessimistically evaluates the readiness of their close environment to vaccinate, will show enthusiasm in relation to participation in information work to promote mass vaccination - a measure that is leading in terms of effectiveness in the assessments of the surveyed plasma donors. Convincing from the broadcasting of anti-pandemic messages by these "pessimistic skeptics" is also not worth expecting. Thus, the potential of plasma donors 
in hypothetical information work to promote mass vaccination and other anti-pandemic control measures is unevenly distributed across the group: it makes no sense to involve in such work those who believe the fight against the pandemic (in particular, the promotion of mass vaccination) is hopeless, makes no sense. And the main emphasis should be placed on those who see the prospects for promoting vaccination, at least in the close environment, encouraging - that is, on a third of the group. Whether it will be effective to join that part of the group that we have designated as "neutrals" to them is a question for future clarifying studies. In general, the ideas of plasma donors about the

\section{REFERENCES}

[1] Ahmed Hassan Mohammed Hassan, Arfan Ali Mohammed Qasem, Walaa Faisal Mohammed Abdalla and Omer H. Elhassan (2021), "Visualization \& Prediction of COVID-19 Future Outbreak by Using Machine Learning", International Journal of Information Technology and Computer Science (IJITCS), vol. 13, no. 3, pp.16-32. DOI: $10.5815 /$ ijitcs.2021.03.02

[2] Aderonke B. Sakpere, Ayomiposi G. Oluwadebi, Oluwatoyin H. Ajilore and Lauretta E. Malaka (2021), "The Impact of COVID-19 on the Academic Performance of Students: A Psychosocial Study Using Association and Regression Model", International Journal of Education and Management Engineering (IJEME), vol. 11, no. 5, pp. 32-45. DOI: $10.5815 /$ ijeme.2021.05.04

[3] Joseph Isabona and Divine O. Ojuh (2021), "Machine Learning Based on Kernel Function Controlled Gaussian Process Regression Method for In-depth Extrapolative Analysis of Covid-19 Daily Cases Drift Rates ", International Journal of Mathematical Sciences and Computing (IJMSC), vol. 7, no. 2, pp. 14-23. DOI: $10.5815 /$ ijmsc.2021.02.02

[4] Raghad Khweiled, Mahmoud Jazzar and Derar Eleyan (2021), "Cybercrimes during COVID -19 Pandemic ", International Journal of Information Engineering and Electronic Business(IJIEEB), vol. 13, no. 2, pp. 1-10. DOI: $10.5815 /$ ijieeb.2021.02.01

[5] Mirza Waseem Hussain, Tabasum Mirza and Malik Mubasher Hassan (2020), "Impact of COVID-19 Pandemic on the Human Behavior ", International Journal of Education and Management Engineering (IJEME), vol. 10, no. 5, pp.35-61. DOI: 10.5815/ijeme.2020.05.05 effectiveness and prospects of combating the pandemic are predominantly rational, focused on scientific and medical discourse, and those from plasma donors who have completed secondary or higher education, as well as are guided by the opinion of medical professionals and WHO representatives and believe a large-scale an information campaign is a hypothetically convincing tool for promoting vaccination, are the most optimistic in assessing the readiness of their environment to be vaccinated, and have the greatest potential for information promotion of mass vaccination and other anti-pandemic control measures.

[6] Kravchuk, P. and Sushko, I. (2021), "Information policy and communication of restrictions on freedom of movement during a pandemic", Analiticheskij centr «Evropa bez bar'erov», available at: https://europewb.org.ua/wpcontent/uploads/2021/01/Komunikatsiyaobmezhen-pandemiya-analitzvit.pdf

[7] Vlijanie pandemii koronovirusa COVID-19 na prava, svobody $i$ bezopasnosti cheloveka $v$ informacionnoj sfere [Impact of the COVID-19 coronavirus pandemic on human rights, freedoms and security in the information sphere], Materialy nauchno-prakticheskoj studencheskoj konferencii, 12 maja $2020 \mathrm{~g}$. Kiev, available at: http://ippi.org.ua/sites/default/files/zbirnik_vid_ 12.05.pdf

[8] Sutton, R.M. and Douglas, K.M. (2020), "Conspiracy theories and the conspiracy mindset: implications for political ideology", Current Opinion in Behavioral Sciences, vol. 34, pp. 118122. DOI: 10.1016/j.cobeha.2020.02.015

[9] Tangcharoensathien V., Calleja, N. Nguyen, T. Purnat, T. and et. al. (2020), "Framework for managing the COVID-19 infodemic: Methods and results of an online, crowdsourced who technical consultation", Journal of Medical Internet Research, vol. 22 (6), art. no. e19659. DOI: $10.2196 / 19659$

[10] Litovchenko, A.D. Bojko, D.N. Nehaenko, O.V. Jashkina, D.D. and Muradjan, E.S. (2021), "Donory plazmy v social'no-informacionnom pole v uslovijah pandemii", Science and Education a New Dimension. Humanities and Social Sciences, vol. IX(47), I.: 258, pp. 42-46. DOI: 10.31174/SEND-HS2021-258IX47-09

[11] Liu, Q. Zheng, Z. Ming, WK. and et al. (2020), "Health Communication Through News Media During the Early Stage of the COVID-19 Outbreak in China: Digital Topic Modeling 
Approach", Journal of Medical Internet Research, vol. 22(4). DOI: 10.2196/19118

[12] Brennen, J.S. Simon, F.M. Howard, P.N. and Nielsen, R.K. (2020), “Types, sources, and claims of COVID-19 misinformation", Reuters Institute for the Study of Journalism, University of Oxford; available at: https://reutersinstitute. politics.ox.ac.uk/types-sources-and-claimscovid-19-misinformation

[13] Who.int. (2020), "Landscape of COVID-19 candidate vaccines - 12 November 2020", World Health Organisation, available at: https://www.who.int/publications/m/item/draftlandscape-of-covid-19-candidate-vaccines
[14] Greenhalgh, T. Schmid, M.B. Czypionka, T. Bassler, D. and Gruer, L. (2020), "Face masks for the public during the covid-19 crisis", The BMJ, vol. 369, art. no. m1435. DOI: $10.1136 /$ bmj.m1435

[15] Bennett, M. Should (2020), "I do as I'm told? Trust, experts, and covid-19", Kennedy Institute of Ethics Journal, vol. 30 (3-4), pp. 243-263. DOI: $10.1353 /$ ken.2020.0014 